\title{
Abundance and distribution of tiger prey base at Bardia- Katarniyaghat corridor forest, Nepal
}

\author{
A. Karki ${ }^{1}$, S. R. Jnawali ${ }^{2}$, S. Adhikari ${ }^{3}$ and S. K Sharma ${ }^{4}$
}

\begin{abstract}
mong the total eight species of tigers, only five species survive today (Wikramanayake et al., 1998). Due to loss of habitats, poaching, and trade of tiger body parts, its population across its range is decreasing sharply. Royal Bengal Tiger, Panthera tigris tigris (here in after referred to as tiger) survive only in small, isolated protected areas of India, Nepal, Bhutan, Bangladesh and Myanmar (Bagale, 2005). Tiger has been used as flagship species of wildlife conservation in several Asian countries since the early 1970's (Shrestha, 2004). Densities of tiger appear to be primarily a function of prey densities (Karanth and Nicholos, 2002). As the density of prey declines in a particular area, the number of breeding females decreases, which ultimately taper the population in smaller size than that particular area can support ecologically.
\end{abstract}

Wild ungulates are the major prey base of the tiger and these species have a key role in maintaining the tiger populations. Spotted deer (Axis axis), sambar deer (Cervus unicolor), swamp deer (Cervus duvauceli), hog deer (Axis porcinus), barking deer (Muntiacus muntjac), wild boar (Sus scorfa), gaur bison (Bos gaurus) and sometimes langur(Semnopithecus entellus) comprise the main prey species for tigers in Nepal. Sometimes blue bull (Boselaphus tragocamelus) and four horned antelope (Tetracerus quadricornis) are also eaten but their distribution is very limited. Domestic lives are occasionally preyed upon in peripheral habitats (Bagale, 2005). The low prey densities within the habitat leads to lower encounter rates of tigers with their prey resulting in greater effort to find prey, and much higher energy expenditure per kill (Sunquist and Sunquist, 1989). So prey depletion should be explicitly recognized as a threat to persistence of tiger apart from other anthropogenic factors.

Although, tigers have been known to feed on wide variety of animals, a marked preference for medium to large sized ungulates has been documented in different habitats (Schaller, 1967). Medium to large sized ungulates comprise the bulk of the tiger's diet, of which spotted deer and sambar constitute approximately 55\%-65\% (Karanth and Sunquist, 1995).

\section{Materials and methods}

In order to determine abundance, distribution and habitat preference of tiger prey base, this study was conducted at Bardia-Katarniyaghat forest corridor of western Nepal, which connects Bardiya National Park of Nepal and Katarniyaghat Wildlife Sanctuary of India.

Transect method modified from Smith et al. (1998) was used to sample the prey base. Each sampling unit was a $625 \mathrm{~m}$ long straight line transect with 25 circular plots spaced $25 \mathrm{~m}$ apart with $10 \mathrm{~m}^{2}$ plot size. Pellet counts were done in a series of small sized plots along a line transect which is considered efficient in terms of its power and time required (Neff, 1968). Distance between adjacent and parallel transect was maintained at $100 \mathrm{~m}$.

A total of 40 transects and 1000 circular plots of $10 \mathrm{~m}^{2}$ were taken. Ten transects were taken in each habitat type i.e. Sal forest, Riverine forest, Khair-Sissoo forest and grass land. Detection probability was considered as $100 \%$, because plots were small and searched carefully.

Following calculations were done to analyze the data.

Density: Density of pellet groups per plot was taken as an index of abundance.

Density $=$ total number of pellets groups present in all plots studied / total plots studied

Distribution: Distribution pattern of ungulates was analyzed by calculating ratio of variance and mean $\left(\mathrm{S}^{2} / \mathrm{a}\right)$ following (Odum, 1996)

$$
\begin{gathered}
\left(\mathrm{S}^{2} / \mathrm{a}\right)=1 \text { (random distribution) } \\
\left(\mathrm{S}^{2} / \mathrm{a}\right)<1 \text { (regular distribution) } \\
\left(\mathrm{S}^{2} / \mathrm{a}\right)>1 \text { (clumped distribution) } \\
\text { Where } \mathrm{S}^{2}=\text { variance }=1 / \mathrm{n} \sum(\mathrm{x}-\mathrm{a})^{2} \\
\mathrm{x}=\text { sample value; } \mathrm{a}=\text { mean value }
\end{gathered}
$$

Chi- Square contingency test was used to find out significant differences in the distribution of prey in different studied samples.

\footnotetext{
${ }^{1}$ Department of Soil Conservation and Watershed Management, Babarmahal, Kathmandu., Nepal. E-mail: clickajaya@gmail.com

${ }^{2}$ Hariyo Ban Program, WWF Nepal.

${ }^{3}$ Conservation and Sustainable Use of Wetlands in Nepal, Babarmahal, Kathmandu, Nepal.

${ }^{4}$ Swedish University of Agricultural Science, Sweden
} 


$$
\text { Chi-Square }\left(\lambda^{2}\right)=\Sigma(x-a)^{2} / a
$$

Where $\mathrm{x}=$ observed (or sample) value; $\mathrm{a}=$ expected value (or mean value)

Habitat preference was calculated following (Pokhrel, 1996)

Habitat preference $(\mathrm{HP})=(\mathrm{PPE} / \mathrm{TPP}) \times 100$

Where,

$\mathrm{PPE}=$ Pellet present in each habitat type

$\mathrm{TPP}=$ Total pellet present in all the habitat type

\section{Results and discussion}

\section{Prey abundance}

Highest prey abundance was recorded for spotted deer, and the lowest for hog deer (Fig. 1). In overall, lower prey abundance was recorded than the previous studies (Adhikari and Khadka, 2009); it could be due to conduction of study subsequent to rainfall or smaller geographic coverage during transect survey than the previous studies.

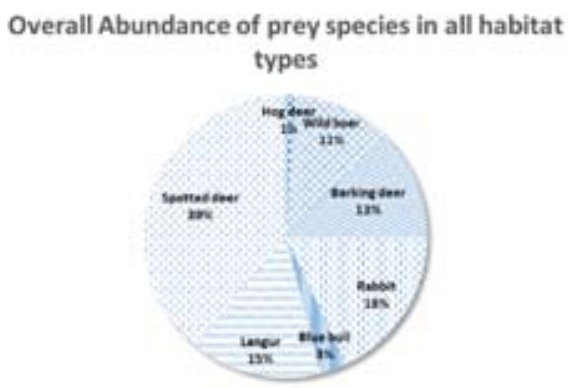

Fig. 1: Overall abundance of prey species in all habitat types

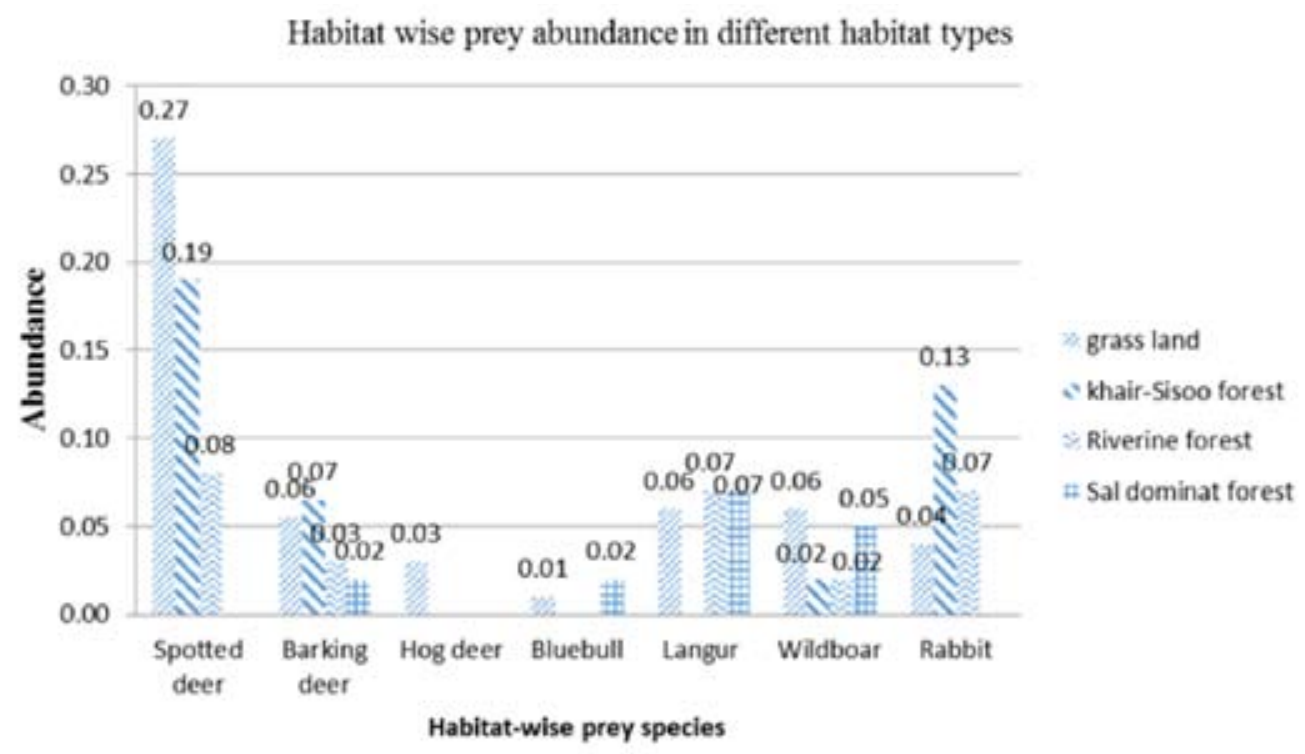

Fig. 3: Species wise prey distribution in different habitats

\section{Pellet group abundance}

Highest prey base abundance was found in grassland with a mean of 0.56 pellet group (all prey species) per plot followed by Khair-Sissoo forest (0.3960), Riverine forest (0.248) and Sal dominant forest (0.192) (Fig. 2). Species and habitat wise abundance suggest that grassland and Khair-Sissoo forest are most important habitats for prey abundance.

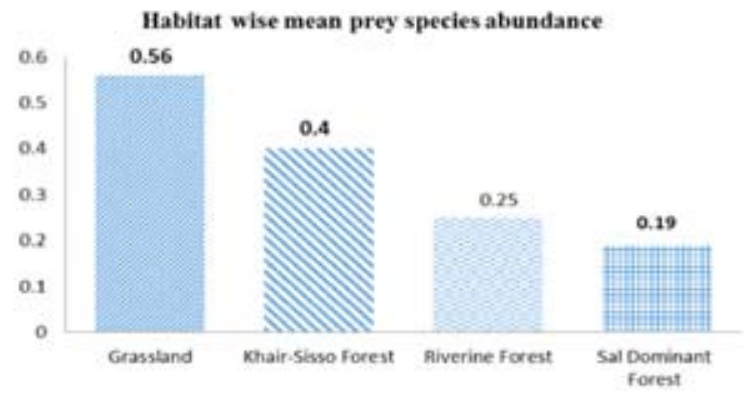

Fig.2: Habitat wise mean prey species abundance

\section{Prey distribution}

Figure 3 shows that most abundant prey of tiger is spotted deer which is highly found in grassland. The rabbit is only emergency food of tiger in this habitat and tiger attacks on it are rare. Barking deer, hog deer and blue bull have very low abundance, so they have minimum chance of being attacked, although they are preferred food of tiger. Wild boar and langur are staple food of tiger and feeds occasionally in deficiency period. 


\section{Habitat preference}

The most preferred habitat of prey species was found to be grassland with $38.35 \%$ preference followed by $29.79 \%, 18.58 \%$ and $13.28 \%$ for Khair-Sissoo forest, Riverine forest and Sal dominant forest, respectively (Fig.4). This also suggests that grassland is the most preferred habitat of prey base and important for maintaining the tiger population.

\section{Habitat preference by prey species}

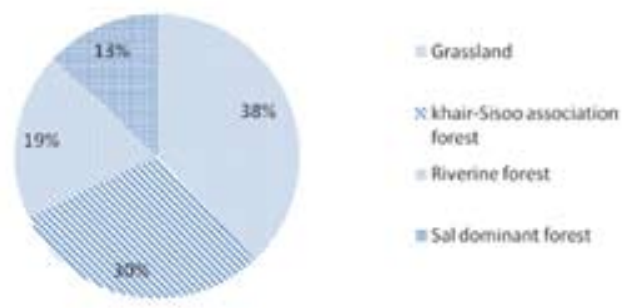

Fig. 4: Habitat preference by prey species

Spotted deer's preference was found the highest in grassland which is followed by Khair-Sissoo forest and Riverine forest (Fig. 5). Spotted deer's pellets were not recorded in Sal dominant forest. The blue bull was distributed only in Sal dominant forest and grassland. The most preferred habitat of barking deer was found to be Khair-Sissoo forest followed by grassland, Sal dominant forest and Riverine forest, respectively. Besides, its sedentary and shy nature along with anti-predator strategy of being inconspicuous makes it to reside more in dense forest than in open and disturbed areas. Similar result was found in this study.

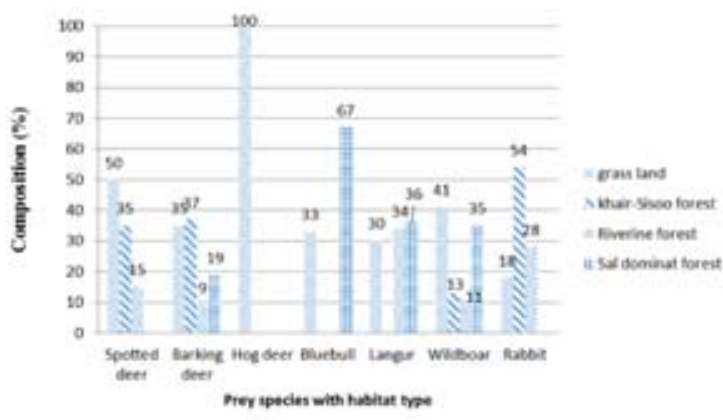

Fig. 5: Habitat preference (\%) by prey species

Hog deer prefer grass-covered delta islands, or open phantas. During the day, hog deer shelter in tall grasslands (Neff et al., 1991). Hog deer usually inhabit grassland, and seldom seen in forest (Pokhrel, 2005). Present results also supported this statement since Hog deer's pellets were recorded only in grassland.
Wild boar was found in all habitat types. Grassland and Sal dominant forests were its preferred habitats whereas Riverine and KhairSissoo forests were the second preferred habitats. Rabbit's pellets were found the highest in KhairSissoo forest followed by Riverine forest and grassland. Langur was found the highest in Sal dominant forest followed by Riverine forest and grassland (Fig. 5).

\section{Distribution Pattern}

Habitat influencing factors needs to be known for species conservation. Distribution pattern of prey is one of the means for relating with distribution pattern of tiger. Distribution pattern of prey in different habitat types was calculated and found to be of clumped type which was verified by calculating variance and mean ratio $\left(\mathrm{S}^{2} / \mathrm{a}\right)$. The value obtained was,

$$
\mathrm{S}^{2} / \mathrm{a}=4.15
$$

Since the value obtained is greater than 1 . So we can conclude that distribution pattern of prey is of the clumped type.

\section{Conclusion}

Abundance of prey species was found higher in grassland and Khair-Sissoo forest. Properly managed these habitats could help in stabilizing the tiger population. Sal dominant forest was found with lowest abundance of prey species compared to other habitats. Distribution pattern of prey species was found to be of clumped type with the highest pellet group recorded in grassland, this shows that prey base distribution is highest in grassland with clumped type. Relative index of prey species was found to be 0.344 mean pellets per $10 \mathrm{~m}^{2}$. High distribution and abundance of prey species suggested that the grassland areas of this corridor are better habitats for wild ungulate species that explains presence of good number of tigers.

\section{References}

Adhikari, S. and Khadka, A. 2009. Study on Relative abundance and distribution of Tiger prey Base (Ungulates) in Khata corridor, Bardia National Park. Journal of Science, Engineering and Technology 5 (1): 121-135.

Bagale, R. P. 2005. A study on Tiger- prey relationship in Chitwan National Park, Nepal. Unpublished. 
Karanth, K. U. and Nicholos, J. D. 2002. Monitoring Tigers and Their Prey. A Manual for Researchers, Managers and Conservationists in Tropical Asia. Centre for wildlife studies, Bangalore, India.

Karanth, K.U. and Sunquist M. 1995. Prey selection by tiger, leopard and dhole in tropical forest. Journal of Animal Ecology 64: 439-450.

Neff, D. J.1968. The pellet- group count technique for big game trend, census, and distribution: a review. Journal of Wildlife Management 32: 597-614.

Odum, E. P.1996. Fundamental of Ecology, Third Edition, Nataraj Publishers, Dehradun, India

Pokhrel, C. P.1996. Food and Habitat Utilization of Swamp deer (Cervus duvauceli) in the Bardia National Park. M.Sc. Dissertation, Tribhuvan University, Nepal.

Schaller, G.B.1967. The Deer and the Tiger. University Chicago Press, Chicago, USA.
Shrestha, M. K.2004. Relative Ungulate Abundance in a Fragmented Landscape Implication for Tiger Conservation. $\mathrm{PhD}$ Thesis, University of Minnesota, USA.

Smith, J. L.D., Ahearn, S. C. and McDougal, C. 1998. Landscape analysis of tiger distribution and habitat quality in Nepal. Conservation Biology 12: 1338-1346.

Sunquist, M. E. and Sunquist F. C.1989. Ecological constraints on predation by large Felids. In Carnivore Behavior, Ecology and Evolution (ed.) J. L. Gittleman, Chapman and Hall, London, UK.

Wikramanayake, E. D., Dinerstein,E, Robinson, J. G., Karanth, U., Rabinowitz, A., Olson, D., Mathew, T., Hedado, P., Conner, M., Hemley, G., and Bolze, D. 1998. An ecologybased method for defining priorities for large mammal conservation: the tiger as a case study. Conservation Biology 12:865-878. 